\title{
Fatores de risco associados à infecção por Toxoplasma gondii em ovinos e caprinos no estado de Pernambuco ${ }^{1}$
}

\author{
Márcia de Figueiredo Pereira ${ }^{2}$, Rodolfo de Moraes Peixoto ${ }^{3}$, Hélio Langoni ${ }^{4}$, Haroldo \\ Greca Junior ${ }^{5}$, Sérgio Santos de Azevedo ${ }^{6}$, Wagnner José Nascimento Porto ${ }^{7}$, Elizabeth \\ Sampaio de Medeiros ${ }^{7}$ e Rinaldo Aparecido Mota ${ }^{8^{*}}$
}

\begin{abstract}
Pereira M.F., Peixoto R.M., Langoni H., Greca Júnior H., Azevedo S.S., Porto W.J.N., Medeiros E.S., Mota R.A. 2012. [Risk factors for Toxoplasma gondii infection in sheep and goats in Pernambuco, Brazil.] Fatores de risco associados à infecção por Toxoplasma gondii em ovinos e caprinos no estado de Pernambuco. Pesquisa Veterinária Brasileira 32(2):140-146. Departamento de Medicina Veterinária, Universidade Federal Rural de Pernambuco, Rua Dom Manoel de Medeiros s/n, Recife, PE 52171-900, Brazil. E-mail: rinaldo.mota@hotmail.com

This study was conducted to investigate the participation of Toxoplasma gondii in reproductive failure in small ruminants raised in the Litoral/ Zona da Mata and Agreste of the State of Pernambuco, Brazil. Twelve flocks were selected from which 262 samples were collected, 167 from goats and 95 from sheep. Indirect Imunofluorescent Antibody Reaction (IFA) technique was used to detect antibodies anti-Toxoplasma gondii. A questionnaire was applied in flocks to identify risk factors associated with infection. Positive animals were found in $100 \%$ of the farms. Among 167 samples of goat serum analyzed, $31.7 \%$ were positive, whereas from 95 samples of sheep, $16.9 \%$ were positive. Results of brucellosis tests were negative for $100 \%$ of analyzed samples. For sheep, no significant association was found; however, for goats, there was a significant association $(\mathrm{p}<0.05)$ for intensive handling $(\mathrm{OR}=2.40)$, milk exploration $(\mathrm{OR}=2.10)$, animals originating from other states $(\mathrm{OR}=7.89)$ and natural breeding $(\mathrm{OR}=5.69)$. It was concluded that infection for $T$. gondii is spread in studied goat and sheep flocks and that sanitary measures must be adopted to control risk factors for infection.
\end{abstract}

INDEX TERMS: Indirect imunofluorescent antibody reaction, Toxoplasma gondii, risk factors.

\footnotetext{
${ }^{1}$ Recebido em 27 de julho de 2011.

Aceito para publicação em 21 de outubro de 2011.

2 Área de Patologia, Departamento de Medicina Veterinária, Universidade Federal Rural de Pernambuco (UFRPE), Av. Dom Manoel de Medeiros s/n, Dois Irmãos, Recife, PE 51171-900, Brasil.

${ }^{3}$ Bolsista de Iniciação Científica e Discente do Curso de Medicina Veterinária da UFRPE, Av. Dom Manoel de Medeiros s/n, Dois Irmãos, Recife, PE.

${ }^{4}$ Departamento de Higiene Veterinária e Saúde Pública, Faculdade de Medicina Veterinária e Zootecnia, Universidade Estadual Paulista (Unesp), Distrito de Rubião Júnior, Botucatu, SP 18618-000, Brasil.

${ }^{5}$ Núcleo de Pesquisas em Zoonoses, Unesp, Distrito de Rubião Júnior, Botucatu, SP 18618-000.

${ }^{6}$ Unidade Acadêmica de Medicina Veterinária, Centro de Saúde e Tecnologia Rural, Universidade Federal de Campina Grande (UFCG), Campus de Patos, Patos, PB 58700-000, Brasil.

${ }^{7}$ Campus Arapiraca da Universidade Federal de Alagoas, Fazenda São Luiz s/n, Zona Rural, Viçosa, AL 57700-000, Brasil.

${ }^{8}$ Departamento de Medicina Veterinária, UFRPE, Av. Dom Manoel de Medeiros s/n, Dois Irmãos, Recife, PE. *Autor para correspondência: rinaldo.mota@hotmail.com
}

RESUMO-- Objetivou-se com este estudo investigar a participação de Toxoplasma gondii em falhas reprodutivas em pequenos ruminantes de criatórios situados na Zona da Mata e no Agreste do Estado de Pernambuco e que apresentavam histórico de distúrbios reprodutivos. Foram selecionadas 12 propriedades das quais se coletaram amostras de 262 animais, sendo 167 caprinos e 95 ovinos. Realizou-se a pesquisa de anticorpos anti-Toxoplasma gondii, utilizando-se a técnica da Imunofluorescência Indireta (RIFI). Foram aplicados questionários investigativos nas propriedades visitadas para identificar os fatores de risco associados à infecção. Em 100\% das propriedades foram encontrados animais soropositivos. Para T. gondii, das 167 amostras de soro caprino analisadas, $31,7 \%$ foram positivas, enquanto que na espécie ovina, das 95 amostras, $16,9 \%$ foram positivas. Para a espécie ovina, não foram observadas associações significativas. Para os caprinos, houve associação 
significativa $(\mathrm{p}<0,05)$ para as variáveis: manejo intensivo $(\mathrm{OR}=2,40)$, exploração leiteira $(\mathrm{OR}=2,10)$, animais procedentes de outros estados $(\mathrm{OR}=7,89)$ e monta natural $(\mathrm{OR}=5,69)$. Conclui-se que a infecção pelo T. gondii encontra-se disseminada nos rebanhos de caprinos e ovinos estudados e que medidas sanitárias devem ser adotadas para controlar os fatores de risco identificados neste estudo.

TERMOS PARA INDEXAÇÃO: Reação de Imunofluorescência Indireta, Toxoplasma gondii, fatores de risco.

\section{INTRODUÇÃO}

A criação de ovinos e caprinos representa uma das principais atividades econômicas do Nordeste, no entanto, ainda apresenta um baixo desempenho produtivo e reprodutivo (Barros 2004) devido a diversos fatores que acarretam sérios problemas sanitários (Vieira et al. 1998).

No contexto das doenças reprodutivas de pequenos ruminantes, destaca-se a toxoplasmose, uma enfermidade parasitária causada pelo coccídeo Toxoplasma gondii, que apresenta implicações reprodutivas para algumas espécies, inclusive o homem, aves e mamíferos domésticos e silvestres (Luzon et al. 1997).

Vários trabalhos já foram realizados em todo o mundo, demonstrando a alta prevalência da infecção por T. gondii em ovinos e caprinos. Destacam-se aqueles realizados nos Estados Unidos (Dubey \& Adams 1990), em Gana (Van Der Puije et al. 2000), na Itália (Masala et al. 2005), e também no Brasil, onde foram encontradas taxas de caprinos e ovinos sororeagentes para T. gondii variando de 21 e $70 \%$ (Linhares et al. 1990, Sposito Filha et al. 1992, Sella et al. 1994, 1995, Araújo et al. 1998, Martins et al. 1998, Garcia et al. 1999, Langoni et al. 1999, Stachissini 2005). No Estado de Pernambuco, a prevalência de caprinos sororeagentes foi de 35,3 a $42 \%$, respectivamente (Oliveira et al. 1995, Silva et al. 2003).

0 objetivo deste trabalho foi estudar a freqüência de animais soro-reagentes e identificar os fatores de risco associados à infecção por T. gondii em caprinos e ovinos criados nas regiões da Zona da Mata e Agreste do Estado de Pernambuco, Brasil.

\section{MATERIAL E MÉTODOS}

O trabalho consistiu de um estudo transversal para determinar a frequência de caprinos e ovinos infectados por Toxoplasma gondii e testar a relação entre o status sorológico e alguns possíveis fatores de risco.

0 estudo foi realizado em propriedades do estado de Pernambuco, Brasil que situa-se a centro-leste da Região Nordeste do Brasil. Foram utilizados neste estudo 262 animais, sendo 95 ovinos e 167 caprinos procedentes de 12 propriedades rurais localizadas no Litoral/Zona da Mata (municípios de Camaragibe, Jaboatão dos Guararapes, Igarassu e São Lourenço da Mata, Vicência) e Agreste (Brejo da Madre de Deus) (Fig.1). Após anti-sepsia foi coletada amostra de dez $\mathrm{mL}$ de sangue, mediante punção da veia jugular utilizando agulhas hipodérmicas descartáveis 40x12. Os tubos contendo as amostras sanguíneas permaneceram em repouso para retração do coágulo e posteriormente foram centrifugadas para a obtenção do soro, que foram acondicionados em tubos tipo "eppendorf" e mantidos congelados a -20ํㅡ até o momento da realização dos testes sorológicos.

Foi utilizada amostragem não-probabilística por conveniência de acordo com Thrusfield (2004) e as amostras foram coletadas em propriedades com histórico de problemas reprodutivos.

O exame sorológico foi realizado pelo Serviço de Diagnóstico de Zoonoses do Departamento de Higiene Veterinária e Saúde Pública da Faculdade de Medicina Veterinária e Zootecnia da Unesp-Botucatu, SP. Para a pesquisa de anticorpos anti-Toxoplasma gondii, empregou-se a técnica de Imunofluorescência Indireta, utilizando-se anticorpos anti-IgG-caprina e anti-IgG-ovina conjugado a isotiocianato de fluoresceína na diluição de 1:100 (anti-sheep IgG), lote F5137 e 1:100 (anti-goat IgG), lote F2016. Diluições do soro na razão quatro (1:16 a 1:4096) foram testadas e reações à diluição 1:64 ou maior foram consideradas positivas (Mainar et al. 1996).

Para o estudo dos fatores de risco foram utilizados questionários aplicados pelo mesmo entrevistador e constituídos de 34 perguntas fechadas, sendo sete relativas a informações sobre o criador, 21 sobre características gerais da propriedade como espécie, raça (pura ou mestiça), tipo de produção (leite ou carne), sistema de manejo (intensivo, semi-intensivo ou extensivo), aspectos sanitários (freqüência de limpeza das instalações, presença de assistência veterinária) e manejo reprodutivo (monta natural, monta controlada ou inseminação artificial) e seis sobre o status sanitá-

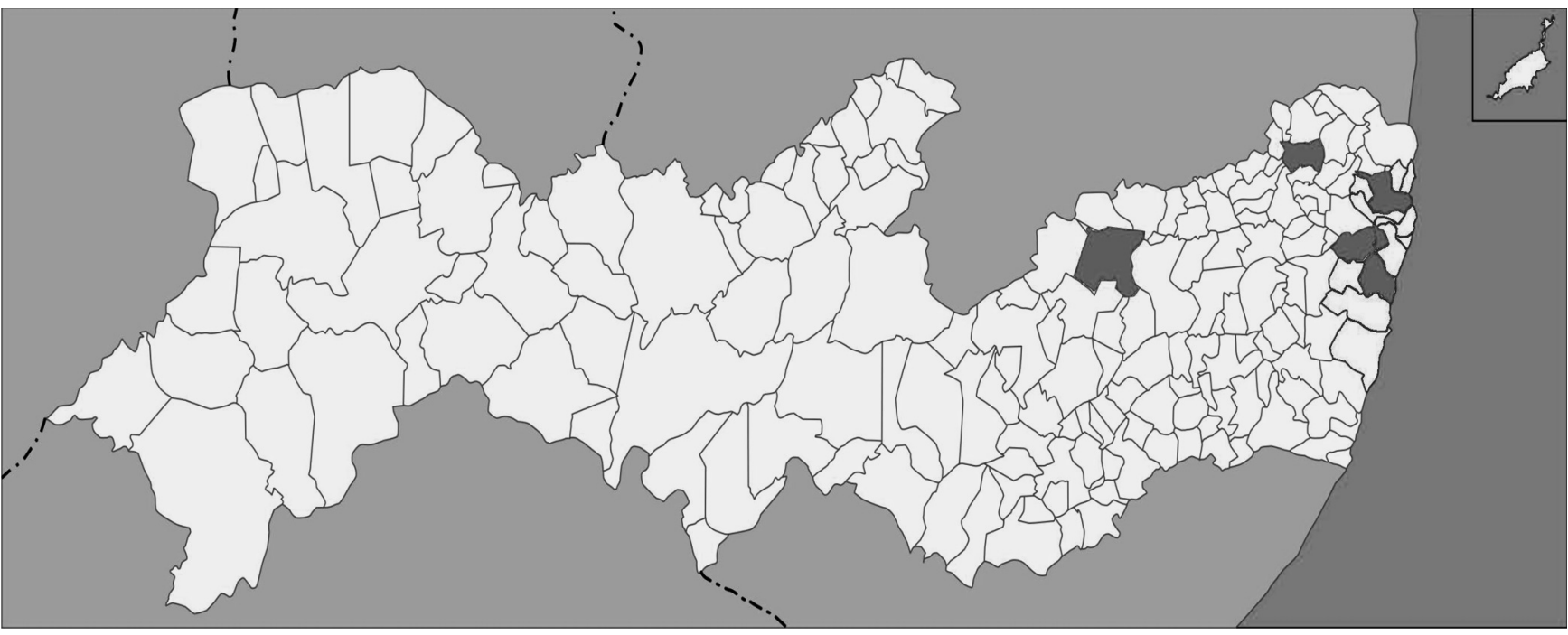

Fig. 1: Municípios estudados localizados na Zona da Mata e Agreste de Pernambuco. 
rio do rebanho (presença de doenças, especialmente problemas reprodutivos, além de pneumonia e conjuntivite).

A análise de fatores de risco foi efetuada em duas etapas compreendendo a análise univariada e multivariada. Na primeira, cada variável independente foi cruzada com a variável dependente (condição sanitária do animal). As que apresentaram um valor de $\mathrm{p} \leq 0,15$ pelo teste de qui-quadrado (Zar 1999) foram selecionadas e oferecidas para a análise multivariada, utilizando-se a regressão logística múltipla (Hosmer \& Lemeshow 2000), para a definição de um modelo que melhor identificasse os fatores de risco. 0 nível de significância adotado na análise múltipla foi de 5\%. 0 ajuste do modelo final foi verificado com o teste de Hosmer e Lemeshow e um $\mathrm{p} \geq 0,05$ indica que o modelo está ajustado. As análises foram realizadas com o programa SPSS for Windows versão 13.0.

A associação entre problemas reprodutivos e soropositividade para Toxoplasma gondii foi efetuada com o cálculo do Risco Relativo e respectivo intervalo de confiança de 95\% (IC 95\%) (Thrusfield 2004). 0 teste de hipóteses foi realizado com o teste de qui-quadrado ou teste exato de Fisher (Zar 1999).

\section{RESULTADOS E DISCUSSÃO}

Das 167 amostras de soro caprino e 95 de ovino analisadas, $53(31,8 \%)$ e $16(16,9 \%)$ foram positivas, respectivamente (Quadro 1).

Quadro 1. Recíproca dos títulos de anticorpos anti-Toxoplasma gondii pela Reação de Imunofluorescência Indireta, em amostras de soro de ovinos e caprinos das regiões do Litoral/ Zona da Mata e Agreste do Estado de Pernambuco

\begin{tabular}{lcccccccc}
\hline \multirow{2}{*}{ Espécie } & \multirow{2}{*}{$\mathrm{N}$} & \multicolumn{9}{c}{ Títulos (\%) } & Total de \\
\cline { 3 - 9 } & & Negativo & 16 & 64 & 256 & 1024 & 4096 & positivos \\
\hline \multirow{2}{*}{ Caprinos } & 167 & 72 & 42 & 24 & 20 & 8 & 1 & 53 \\
& & $(43,1)$ & $(25,1)$ & $(14,4)$ & $(12,0)$ & $(4,8)$ & $(0,6)$ & $(31,8)$ \\
Ovinos & 95 & 36 & 43 & 15 & 1 & - & - & 16 \\
& & $(37,9)$ & $(45,3)$ & $(15,8)$ & $(1,1)$ & & & $(16,9)$ \\
Total & 262 & 108 & 85 & 39 & 21 & 8 & 1 & 69 \\
& & $(41,2)$ & $(32,4)$ & $(14,9)$ & $(8,0)$ & $(3,1)$ & $(0,4)$ & $(26,4)$
\end{tabular}

Os títulos de anticorpos mais frequentes observados para a espécie caprina foram 16 (25,1\%), 64 (14,4\%) e 256 (12,0\%); o maior título sorológico observado nos caprinos foi 4096 (0,6\%). Em ovinos, o maior título observado foi $256(1,1 \%)$ e os títulos mais frequentes foram $16(45,3 \%)$ e $64(15,8 \%)$. Títulos variando entre 16 e 1024 foram observados em $56,3 \%$ dos caprinos e $62,2 \%$ dos ovinos o que pode ser sugestivo de infecção latente (Camargo 1975).

Das seis propriedades com criação mista de ovinos e caprinos, quatro apresentaram a frequência de caprinos positivos maior que a de ovinos. No total, a frequência de caprinos soropositivos $(31,8 \%)$ foi maior que a de ovinos (16,9\%) (Quadro 1) e a diferença entre as espécies foi significativa $(\mathrm{p}<0,01)$ e a OR para caprinos foi de 2,30 .

A diferença na frequência de anticorpos anti-Toxoplasma gondii observada entre ovinos e caprinos neste estudo também foi verificada anteriormente por Silva et al. (2003) na Zona da Mata e Agreste do Estado de Pernambuco, sendo essa variação comum entre as espécies como relatado por Garcia-Vázquez et al. (1990) e Gondim et al. (1999).

Os resultados obtidos neste estudo encontram-se dentro dos limites de variação citados por diferentes autores que realizaram inquéritos soro-epidemiológicos em diferentes regiões do país, utilizando diferentes técnicas de diagnóstico. Observaram variação de 14,47\% a 92,4\% de soropositividade para ovinos e caprinos (Mainardi et al. 2003). A frequência de variação para caprinos encontra-se entre $14,47 \%$ e $100 \%$ e para ovinos de $17,5 \%$ (Oliveira-Sequeira et al. 1993) a 92,00\% (Chiari et al. 1987, Machado \& Lima 1987, Linhares et al. 1990, Araújo et al. 1998, Martins et al. 1998, Gondim et al. 1999, Langoni et al. 1999).

Comparando os resultados obtidos neste estudo com aqueles relatados por Silva et al. (2003) que obtiveram $35,3 \%$ de ovinos e 40,4\% de caprinos positivos, respectivamente e Oliveira et al. (1995) que relataram 42,0\% para caprinos, na mesma região do Estado de Pernambuco, observa-se, se forem incluídos todos os animais reagentes, que houve um incremento no número de animais soropositivos. Isso pode sugerir a disseminação deste parasito nas propriedades dessa mesma região. Entretanto, é necessário ressaltar que os autores citados trabalharam com títulos iguais ou maiores que 16, enquanto que neste trabalho, somente foram considerados positivos resultados iguais ou maiores a 64 .

Na Paraíba, Alves et al. (1997) também observaram uma frequência de soro-reagentes mais baixa $(26,8 \%)$, para caprinos, enquanto que Sella et al. (1994), no Paraná, relataram um percentual de 30,71\% de caprinos sorologicamente positivos. Este último trabalho também considerou o título de 16 (13,07\%) como inespecífico.

Em todas as propriedades foram encontrados animais reagentes para T. gondii.

A maior frequência de animais soropositivos para $T$. gondii foi observada na propriedade $2(80,0 \%)$ e a menor na propriedade $11(4,2 \%)$. Nesta última foi relatado que cinco cabras abortaram no período de uma semana e que um cabrito morreu antes de completar 24 horas de nascido.

Na propriedade três foi informado que ocorreram aproximadamente cinco casos de abortamento, três natimortos e três borregos morreram antes de completar um mês de vida e observou-se um alto índice de animais soropositivos. Nessa propriedade eram criados aproximadamente 50 ovinos e caprinos mestiços em condições higiênico-sanitárias e de manejo inadequadas. As instalações eram parcialmente cobertas, com piso batido onde os animais permaneciam dia e noite. A criação visava apenas o consumo próprio e os animais eram procedentes de feiras livres de um município vizinho e a alimentação era feita com restos de frutas e legumes da Central de Abastecimento Alimentar de Pernambuco.

Todas as propriedades visitadas relataram a ocorrência de problemas reprodutivos, como infertilidade, repetição de cio, abortamento, natimortos e mortalidade neonatal.

Nos Quadros 2 e 3 estão resumidas as oito variáveis analisadas e comparadas à ocorrência de anticorpos anti- T. gondii em caprinos e ovinos, respectivamente. Para os caprinos, pela análise univariada, observou-se associação significativa para o manejo $(\mathrm{OR}=2,40)$, tipo de exploração $(\mathrm{OR}=2,10)$, origem dos animais $(\mathrm{OR}=7,89)$ e manejo reprodutivo $(\mathrm{OR}=5,69)$. Na análise multivariada, porém, somente os três últimos foram confirmados (Quadro 4). Para a espécie ovina não foram observadas associações significativas para os fatores de risco estudados. 
Quadro 2. Fatores associados à frequência de caprinos soropositivos para Toxoplasma gondii na análise univariada $(\mathbf{p}<0,05)$ nas Regiões do Litoral/ Zona da Mata e Agreste do Estado de Pernambuco

\begin{tabular}{|c|c|c|c|c|c|c|}
\hline Variável & $\mathrm{N}$ & $\%$ & OR & IC 95\% & Qui & $\mathrm{p}$ \\
\hline \multicolumn{7}{|l|}{ Raça } \\
\hline Pura & 45 & 43,2 & 1,99 & $0,91-4,35$ & 3,59 & 0,0581 \\
\hline Mestiça & 123 & 27,6 & & & & \\
\hline \multicolumn{7}{|l|}{ Manejo } \\
\hline Intensivo & 87 & 40,7 & 2,40 & $1,15-5,05$ & 6,53 & 0,0105 \\
\hline Semi-intensivo & 81 & 22,2 & & & & \\
\hline \multicolumn{7}{|l|}{ Exploração } \\
\hline Leite & 60 & 42,4 & 2,10 & $1,02-4,35$ & 4,74 & 0,0295 \\
\hline Carne & 108 & 25,9 & & & & \\
\hline \multicolumn{7}{|l|}{ Origem } \\
\hline Mesmo município & 21 & 19,0 & & & 15,23 & 0,0016 \\
\hline Outro município & 65 & 35,4 & & & & \\
\hline Outro estado & 20 & 65,0 & & & & \\
\hline Leilão/ exposição & 62 & 21,3 & & & & \\
\hline \multicolumn{7}{|l|}{ Assistência Veterinária } \\
\hline Sim & 62 & 32,3 & 1,04 & $0,50-2,16$ & 0,01 & 0,9116 \\
\hline Não & 106 & 31,4 & & & & \\
\hline \multicolumn{7}{|l|}{ Manejo Reprodutivo } \\
\hline Monta natural & 72 & 51,4 & & & 22,99 & $<0,001$ \\
\hline Monta controlada & 84 & 15,7 & & & & \\
\hline Inseminação artificial & 12 & 25,0 & & & & \\
\hline \multicolumn{7}{|l|}{ Frequência de limpeza } \\
\hline Diária & 52 & 31,4 & & & 1,91 & 0,3844 \\
\hline Semanal & 55 & 38,2 & & & & \\
\hline Mensal & 61 & 26,2 & & & & \\
\hline \multicolumn{7}{|l|}{ Presença de gatos } \\
\hline Sim & 75 & 28,0 & 0,74 & $0,36-1,52$ & 0,78 & 0,3756 \\
\hline Não & 93 & 34,4 & & & & \\
\hline
\end{tabular}

Quadro 3. Fatores associados à frequência de ovinos soro-reagentes para Toxoplasma gondii na análise univariável $(\mathbf{p}<0,05)$ para caprinos criados nas Regiões do Agreste, Zona da Mata e Região Metropolitana do Recife, Pernambuco

\begin{tabular}{|c|c|c|c|c|c|c|}
\hline Variável & $\mathrm{N}$ & $\%$ & OR & IC $95 \%$ & Qui & $\mathrm{p}$ \\
\hline \multicolumn{7}{|l|}{ Raça } \\
\hline Pura & 62 & 12,7 & 0,44 & $0,13-1,49$ & 2,27 & 0,132 \\
\hline Mestiça & 32 & 25,0 & & & & \\
\hline \multicolumn{7}{|l|}{ Manejo } \\
\hline Intensivo & 5 & 20,0 & & & 0,279 & 0,870 \\
\hline Semi-intensivo & 75 & 16,0 & & & & \\
\hline Extensivo & 14 & 21,4 & & & & \\
\hline \multicolumn{7}{|l|}{ Exploração } \\
\hline Leite & - & - & & & & \\
\hline Carne & 94 & 16,8 & & & & \\
\hline \multicolumn{7}{|l|}{ Origem* } \\
\hline Mesmo município & 3 & 33,3 & & & 2,78 & 0,250 \\
\hline Outro município & 13 & 30,8 & & & & \\
\hline Leilão/ exposição & 78 & 13,9 & & & & \\
\hline \multicolumn{7}{|l|}{ Assistência Veterinária } \\
\hline Sim & 75 & 16,0 & 0,76 & $0,19-3,29$ & 0,18 & 0,6726 \\
\hline Não & 19 & 20,0 & & & & \\
\hline \multicolumn{7}{|l|}{ Manejo Reprodutivo } \\
\hline Monta natural & 42 & 16,7 & & & 0,62 & 0,7339 \\
\hline Monta controlada & 10 & 9,1 & & & & \\
\hline Inseminação artificial & 42 & 19,0 & & & & \\
\hline \multicolumn{7}{|l|}{ Frequência de limpeza } \\
\hline Diária & 69 & 15,7 & & & 0,29 & 0,8659 \\
\hline Semanal & 14 & 21,4 & & & & \\
\hline Mensal & 11 & 18,2 & & & & \\
\hline \multicolumn{7}{|l|}{ Presença de gatos } \\
\hline Sim & 36 & 22,2 & 1,75 & $0,52-5,94$ & 1,03 & 0,3108 \\
\hline Não & 57 & 14,0 & & & & \\
\hline
\end{tabular}

Para os caprinos, $43,2 \%$ dos animais de raças puras e $27,6 \%$ dos animais mestiços encontravam-se infectados por T. gondii, respectivamente. Apesar da OR para raça pura em caprinos ter sido 1,99, não houve associação significativa $(p>0,05)$. Em ovinos de raça pura e mestiços foram encontrados $12,7 \%$ e $25,0 \%$ de soropositivos, respectivamente.

Ao contrário do que foi observado nesse estudo, Silva et al. (2003) descreveram diferenças significativas na prevalência de $T$. gondii entre animais de raças puras $(27,1 \%)$ e mestiços $(72,8 \%)$ e atribuíram esta diferença ao menor cuidado higiênico sanitário das criações de animais mestiços.

Os caprinos criados em sistema semi-intensivo apresentaram uma frequência de infecção de $22,2 \%$, enquanto que a frequência para aqueles criados em regime intensivo foi de 40,7\%, com associação significativa $(p<0,05)$ e $0 R=2,40$ (Tabela 2) na análise univariada, não sendo confirmada na análise multivariada. A frequência de ovinos positivos em regime intensivo, semi-intensivo e extensivo foi respectivamente de $16,7 \%, 14,7 \%$ e 23,8\% (Quadro 3). Resultados semelhantes foram descritos por Silva et al. (2003) que também observaram maiores frequências de infecção em caprinos criados em manejo intensivo, mas não em ovinos. Em levantamento realizado na Sérvia com ovinos (Klun et al. 2006) atribuiu-se um maior risco ao manejo semi-extensivo com compartilhamento de pastagens entre as criações.

Em caprinos, observou-se uma maior frequência de positivos entre os animais de produção de leite $(42,4 \%)$ quando comparada com aqueles de corte $(25,9 \%)$. A produção leiteira apresentou associação positiva $(\mathrm{OR}=4,12 ; \mathrm{p}=0,005)$ (Quadro 4). Esta observação está de acordo com os resultados obtidos anteriormente por Machado \& Lima (1987), Opel et al. (1991) e Silva et al. (2003) que também relataram maior prevalência da infecção pelo T. gondii em caprinos procedentes de explorações leiteiras. Além disso, os autores sugerem que nestas criações a maior concentração de animais associada à oferta de alimentos contaminados favorece a transmissão do agente.

De acordo com Machado \& Lima (1987), as criações classificadas como economia mercantil simples, utilizadas por populações pobres das áreas rurais e urbanas como fonte alternativa de renda, apresentam vários fatores relacionados ao maior risco a infecções, como convívio com outras espécies, más condições sanitárias do ambiente, inclusão de sobras de alimentos humanos e de outras espécies na alimentação dos animais, além do confinamento. Estes fatores tornam o ambiente de alto risco para a infecção por

Quadro 4. Fatores de risco para a infecção por Toxoplasma gondii em caprinos das Regiões do Litoral/Zona da Mata e Agreste do Estado de Pernambuco

\begin{tabular}{lccc}
\hline \multicolumn{1}{c}{ Fatores de risco } & Odds Ratio & IC 95 \% & $\mathrm{P}$ \\
\hline Exploração de leite & 4,12 & $1,53-11,08$ & 0,005 \\
Monta natural & 6,09 & $2,22-16,68$ & $<0,001$ \\
Origem & & & \\
Outro município & 15,09 & $3,66-62,23$ & $<0,001$ \\
Outro Estado & 32,51 & $5,73-184,30$ & $<0,001$ \\
Leilão/exposição & 9,37 & $2,02-43,38$ & 0,004 \\
Teste de Hosmer e Lemeshow: $\chi^{2}=2,446 ; \mathrm{p}=0,874$. &
\end{tabular}


T. gondii. Algumas das propriedades visitadas apresentavam características descritas acima.

Todas as propriedades de ovinos utilizadas neste estudo eram constituídas de animais para produção de carne e a frequência de positivos foi de $16,8 \%$.

De acordo com a procedência dos animais, os caprinos adquiridos em outros Estados apresentaram maior frequência de positivos $(65,0 \%)$ do que os procedentes do mesmo município (19,0\%), em municípios vizinhos $(35,4 \%)$ e em leilões e exposições $(21,3 \%)$. Houve associação significativa entre esta variável e a frequência de animais positivos para T. gondii $(\mathrm{p}<0,001)$ (Quadro 4). Em uma análise de tendência linear em proporções, a OR obtida para caprinos procedentes de outros Estados foi 7,89, mas a variável não apresentou associação significativa $(p>0,05)$. Na análise multivariada (Quadro 4), os caprinos procedentes de outros estados apresentaram $\mathrm{OR}=32,51 \mathrm{com}$ associação altamente significativa $(\mathrm{p}<0,001)$.

Uma menor frequência de animais positivos entre os animais adquiridos em leilões e exposições era esperado, uma vez que estes são, geralmente, animais selecionados e de origem conhecida. A seleção de animais é uma das práticas necessárias à redução de risco de infecções (Machado \& Lima 1987). Por outro lado, a alta frequência de soropositivos entre os animais procedentes de outros Estados é um alerta de que a aquisição de animais sem histórico conhecido pode favorecer a disseminação de agentes infecciosos na região.

A frequência de anticorpos anti-T. gondii em ovinos adquiridos de propriedades no mesmo município, em outros municípios e em feiras e exposições foi, respectivamente, de $33,3 \%, 30,8 \%$ e 13,9\%. Para esta espécie não foi verificada associação significativa entre a procedência e a infecção.

0 manejo reprodutivo apresentou associação significativa $(\mathrm{p}<0,001)$ com a soropositividade para T. gondii em caprinos (Quadros 2 e 4), mas não para ovinos (Quadro 3 ). Em uma análise de tendência, a OR para monta natural foi de 5,69 , mas sem associação significativa $(p<0,05)$. No entanto, quando feitas comparações entre monta natural e monta controlada foram observadas diferenças significativas. A OR para a monta natural em relação à monta controlada foi de 5,69, sendo este altamente significativo $(\mathrm{p}<0,0001)$. Quando comparada à inseminação artificial, a monta natural apresentou OR de 3,17, mas sem associação significativa $(p>0,05)$. Na análise multivariada a OR para monta natural foi de 6,09 (p<0,001). Estes resultados confirmam a afirmação de Machado \& Lima (1987) de que a monta controlada é uma das práticas zootécnicas associadas ao menor risco de infecções.

Quanto à limpeza das instalações, as frequências de animais positivos em criações de caprinos que realizavam a limpeza diária, semanal e mensal foram, respectivamente, $31,4 \%, 38,2 \%$ e $26,2 \%$. A maior frequência de ovinos soropositivos foi verificada quando a limpeza era realizada semanalmente $(21,4 \%)$, seguido de limpeza mensal $(18,2 \%)$ e diária $(15,7 \%)$. Contudo, não foi verificada associação significativa $(p>0,05)$ para esta variável e as espécies estudadas.
As frequências de animais positivos em propriedades com e sem presença de felinos foi, respectivamente de $22,2 \%$ e $14,0 \%$ para ovinos e $28,0 \%$ e $34,4 \%$ para caprinos.

A presença dos gatos é relatada na literatura como o principal fator de risco associado à infecção pelo T. gondii, onde ovelhas e cabras podem se infectar ao ingerirem alimentos e água contaminados com oocistos do parasito liberados nas fezes de gatos infectados (Linhares et al. 1990, Luzon et al. 1997). Contudo, neste estudo não foi observada associação estatística significativa $(\mathrm{p}>0,05)$ para esta variável. Existem também outras possíveis formas de transmissão como taquizoítos presentes em secreções e excreções de hospedeiros infectados pelo hábito de lamber um ao outro ou mesmo pelo uso conjunto de bebedouros e comedouros que facilitaria a contaminação por ingestão (Vitor et al. 1991).

A frequência de caprinos positivos nos rebanhos com e sem histórico de abortamento foi de 32,3\% e 30,0\%, respectivamente. Em ovinos, a frequência foi de 19,4\% e $12,1 \%$ com RR de 1,60, porém sem associação significativa $(p>0,05)$. Contudo, a ocorrência de infertilidade, abortamento e mortalidade neonatal não mostrou associação para ambas espécies estudadas (Quadros 5 e 6).

Nos caprinos com e sem histórico de mortalidade neonatal, a frequência de positivos foi de $32,0 \%$ e $31,0 \%$, respectivamente $(\mathrm{RR}=1,03)$ (Quadro 5). Nos ovinos, a freqüência de soropositivos entre os animais com histórico de mortalidade neonatal foi maior $(18,8 \%)$ do que nos animais sem histórico (12,9\%), com OR=1,45 (Quadro 6). No entanto, não houve associação significativa.

Quadro 5. Associação entre problemas reprodutivos e soropositividade para Toxoplasma gondii em caprinos criados no Litoral/Zona da Mata e Agreste do Estado de Pernambuco

\begin{tabular}{lccccc}
\hline \multicolumn{1}{c}{ problema reprodutivo } & $\mathrm{N}^{1}$ & $\%$ & $\mathrm{RR}^{2}$ & $\mathrm{IC} 95 \%{ }^{3}$ & $\mathrm{p}^{4}$ \\
\hline Infertilidade & 135 & 31,1 & 0,91 & $0,53-1,55$ & 0,884 \\
Sim & 32 & 34,4 & & & \\
Não & 127 & 32,3 & 1,08 & $0,63-1,84$ & 0,939 \\
Abortamento & 40 & 30,0 & & & \\
Sim & 125 & 32,0 & 1,03 & $0,62-1,74$ & 0,948 \\
Não & 42 & 31,0 & & & \\
Mortalidade Neonatal & Sim & & & & \\
Não & & & & & \\
\end{tabular}

${ }^{1}$ Número de expostos, ${ }^{2}$ Risco Relativo, ${ }^{3}$ Intervalo de confiança de $95 \%$ para $R R,{ }^{4}$ Se p $>0,05$, então OR não é estatisticamente significativo

Quadro 6. Associação entre problemas reprodutivos e soropositividade para Toxoplasma gondii em ovinos criados no Litoral/Zona da Mata e Agreste do Estado de Pernambuco

\begin{tabular}{lccccc}
\hline \multicolumn{1}{c}{ problema reprodutivo } & $\mathrm{N}^{1}$ & $\%$ & $\mathrm{RR}^{2}$ & $\mathrm{IC} 95 \%{ }^{3}$ & $\mathrm{p}^{4}$ \\
\hline Infertilidade & 78 & 15,4 & 0,65 & $0,24-1,78$ & 0,476 \\
Sim & 17 & 23,5 & & & \\
Não & & & & & \\
Abortamento & 62 & 19,4 & 1,60 & $0,56-4,56$ & 0,542 \\
Sim & 33 & 12,1 & & & \\
Não & & & & & \\
Mortalidade Neonatal & 64 & 18,8 & 1,45 & $0,51-4,14$ & 0,673 \\
Sim & 31 & 12,9 & & & \\
Não &
\end{tabular}

${ }^{1}$ Número de expostos, ${ }^{2}$ Risco Relativo, ${ }^{3}$ Intervalo de confiança de $95 \%$ para $R R,{ }^{4}$ Se p>0,05, então OR não é estatisticamente significativo. 
Estes resultados diferem daqueles observados por Mainar et al. (1996) e Langoni et al. (1999) que relataram associação entre a soropositividade para T. gondii e o histórico de abortamento. Langoni et al. (1999) relataram ainda uma associação entre a frequência de ovinos positivos e a ocorrência de parto distócico e cios irregulares.

Um fator importante e que deve ser investigado refere-se às condições ambientais e climáticas. Estudos realizados na Paraíba, Brasil, registraram uma influência positiva em relação à prevalência de animais soropositivos nas áreas onde a temperatura ambiente é mais amena, a umidade relativa alta, solo úmido e maior precipitação pluviométrica (Alves et al., 1997). Estas características são semelhantes às que ocorrem na Zona da Mata e Região Metropolitana do Recife, em Pernambuco. Porém, nesta investigação não foi observada uma tendência neste sentido.

\section{CONCLUSÃO}

Conclui-se que a infecção por Toxoplasma gondii encontra-se disseminada nos rebanhos de caprinos e ovinos estudados. Para o controle da infecção devem-se considerar os fatores de risco identificados neste estudo, como exploração leiteira, animais oriundos de outros estados e manejo reprodutivo por monta natural.

\section{REFERÊNCIAS}

Alves C.J., Vasconcelos S.A., Navarro I.T. \& Barbosa C.S. 1997. Avaliação dos níveis de aglutininas anti-toxoplasma em soros de caprinos de cinco centros de criação do nordeste do Brasil. Revta Bras. Ciênc. Vet. 4(2):7577

Araújo F.R., Sarti E.C., Balbuena C.B., Carvalho C.M.E. \& Ramos J.K. 1998. Levantamento sorológico para Toxoplasma gondii em caprinos na microrregião de Campo Grande, Mato Grosso do Sul. Revta Ensaios e Ciência 2(2):141-148.

Barros E.E.L. Considerações sobre a produção de caprinos e ovinos no Brasil. Disponível em <http://www.cico.rj.gov.br> Acesso 25 mai. 2004.

Camargo M.E. 1975. Diagnóstico sorológico da toxoplasmose na gravidez. Revta Assoc. Méd. Bras. 21(11):341-346.

Carter G.R. 1986. Fundamentos de Bacteriologia e Micologia Veterinária. Ed. Roca, São Paulo. 249p.

Chiari C.A., Lima W.S, Antunes C.M.F. \& Lima J.D. 1987. Soro-epidemiologia da Toxoplasmose caprina em Minas Gerais, Brasil. Arq. Bras. Med. Vet. Zootec. 39:587-609.

Dubey J.P. \& Adams D.S. 1990. Prevalence of Toxoplasma gondii antibodies in dairy goats from 1982 to 1984. J. Am. Vet. Med. Assoc. 196:295296.

Garcia J.L., Navarro I.T., Ogawa L.\& Oliveira L.C. 1999. Soroprevalência de Toxoplasma gondii em suínos, bovinos, ovinos e eqüinos, e sua correlação com humanos, felinos e caninos, oriundos de propriedades rurais do Norte do Paraná-Brasil. Ciência Rural 29(1):91-97.

García-Vázquez Z., Rosario-Cruz R. \& Solorzano-Salgado M. 1990. Prevalence of antibodies against Toxoplasma gondii in sheep and goats in three states of Mexico. Prev. Vet. Med. 10(1):25-29.

Gondim L.F.P., Barbosa Jr H.V., Ribeiro Filho C.H.A. \& Saeki H. 1999. Serological survey of antibodies to Toxoplasma gondii in goats, sheep, cattle, and water buffaloes in Bahia State, Brazil. Vet. Parasitol. 82(3):273-276

Hosmer D. \& Lemeshow S. 2000. Applied Logistic Regression. John Wiley and Sons, New York. 375p.

IBGE 2006. Instituto Brasileiro de Geografia e Estatística <http://www. sidra.ibge.gov.br> Acesso 10 jul. 2006.
Klun I., Djakovic O.D., Radivojevic S.K. \& Nikolic A. 2006. Cross-sectional survey on Toxoplasma gondii infection in cattle, sheep and pigs in Serbia: Seroprevalence and risk factors. Vet. Parasitol. 135(2):121-131.

Langoni H., Rosa C. \& Marinho M. 1999. Inquérito soroepidemiológico para a toxoplasmose em ovinos no Estado de São Paulo, Brasil. Biológico, São Paulo, 61(1):35-39.

Linhares G.F.C., Dias M.J., Souza A.M. \& Dias Filho F.C. 1990. Anticorpos anti-Toxoplasma gondii em caprinos no município de Goiânia: levantamento sorológico. Anais Escola de Agronomia e Veterinária, Goânia, 20(1):31-37.

Luzon M., Alonso A. \& Gozalo A.Q. 1997. Etiologia y biología: Toxoplasmosis. Revta Ovis, Tratado de Patologia y Produccion Ovina, 52:11-17.

Luzon M., Miro G. \& Gozalo A. 1997. Epidemiologia: Toxoplasmosis. Revista Ovis, Tratado de Patologia y Produccion Ovina, 52:19-32

Machado T.M.M. \& Lima J.D. 1987. Freqüência de anticorpos anti-T. gondii em caprinos criados sob diferentes formas de exploração no Estado de Minas Gerais. Arq. Bras. Med. Vet. Zootec. 39(2):255-264.

Mainar R.C., De La Cruz C., Asensio A., Domínguez L. \& Vázquez-Boland J.A. 1996. Prevalence of agglutinating antibodies to Toxoplasma gondii in small ruminants of the Madrid Region, Spain, and identification of factors influencing seropositivity by multivariate analysis. Vet. Res. Commun. 20(2):153-159.

Martins C.S. \& Viana J.A. 1998. Toxoplasmose: o que todo profissional de saúde deve saber. Clín. Vet. 15:33-37.

Martins J.R., Hancock R., Corrêa B.L. \& Caresér V.H. 1998. Ocorrência de anticorpos contra Toxoplasma gondii em ovinos no município de Livramento, RS: prevalência e implicações epidemiológicas. Pesq. Agropec. Gaúcha 4(1):27-29.

Masala G., Porcu R., Madau L., Tanda D., Ibba B., Satta G. \& Tola S. 2003. Survey of ovine and caprine toxoplasmosis by IFTA and PCR assays in Sardinia, Italy. Vet. Parasitol. 117:15-21.

Oliveira M.P.B., Gurgel A.E.B., Alencar J.V., Pena E.J.M., Machado E.H.L., Alves L.C. \& Faustino M.A.G. 1995. Prevalência de anticorpos antitoxoplasma em caprinos da sub-região da zona da mata do estado de Pernambuco. Revta Bras. Parasitol. Vet. 4(2):195.

Oliveira-Sequeira T.C.G., Amarante A.F.T., Salata E. \& Sogayar R. 1993. Serological survey for Toxoplasma gondii infection in sheep in São Paulo State, Brazil. Veterinária e Zootecnia, Botucatu, 5:121-125.

Opel U., Charleston W.A.G., Pomroy W.E. \& Rommel M.A. 1991. A survey of the prevalence of Toxoplasma infection in goats in New Zealand and a comparison of the latex agglutination and indirect fluorescence tests. Vet. Parasitol. 40:181-186.

Pinheiro R.R., Gouveia A.M.G., Alves F.S.F. \& Haddad J.P.A. 2000. Aspectos epidemiológicos da caprinocultura cearense. Arq. Bras. Med. Vet. Zootec. 52(5):534-543.

Poudevigne F., Inácio Neto A. \& Charles T.P. 1988. Observações sobre epidemiologia dos abortos em caprinos do distrito de Massaroca, Juazeiro, BA. Anais 21을 Congresso Brasileiro de Medicina Veterinária, Salvador, BA.

Rosenberger G. 1993. Exame Clínico dos Bovinos. 3o ed. Guanabara Koogan, Rio de Janeiro. 419p.

Sampaio I.B.M. 1998. Estatística Aplicada à Experimentação Animal. Fundação de Ensino e Pesquisa em Medicina Veterinária e Zootecnia, Belo Horizonte. 221p.

Schwarze, G.M.W. 1970. Embriologia Veterinaria. Ed. Acribia, Zaragoza.

Sella M., Navarro I.T., Freire R.L., Shida P.N. \& Vidotto O. 1994. Epidemiologia da toxoplasmose caprina: levantamento sorológico de Toxoplasma gondii em caprinos leiteiros na microrregião de Londrina, Paraná, Brasil. Revta Bras. Parasitol. Vet.. 3(1):13-16.

Silva A.V., Cunha E.L.P.O, Meireles L.R., Gottschalk S., Mota R.A. \& Langoni H. 2003. Toxoplasmose em ovinos e caprinos: estudo soroepidemiológico em duas regiões do Estado de Pernambuco, Brasil. Ciência Rural 33(1):115-119.

Silva M.U.D. \& Silva E.D.F. 1988. Possíveis causas de aborto em caprinos: diagnóstico, tratamento, profilaxia. Comum. Téc. no.12, Embrapa-CNPC, Sobral. 11p. 
Skjerve E., Waldeland H., Nesbakken T. \& Kapperud G. 1998. Risk factors for the presence of antibodies to Toxoplasma gondii in Norwegian slaughter lambs. Prev. Vet. Med. 35:219-227.

Sposito Filha E, Amaral V., Macruz R., Rebouças M.M., Santos S.M. \& Drumond L.S. 1992. Toxoplasma gondii em ovinos: isolamento do parasita a partir de diafragmas de animais procedentes do Estado do Rio Grande do Sul e abatidos em matadouros de São Paulo, para consumo humano. Revta Bras. Parasitol. Vet. 1(2):117-119.

Stachissini A.V.M. 2005. Toxoplasma gondii e Neospora caninum em caprinos do estado de São Paulo: perfis soro-epidemiológicos e co-infecção com o vírus da artrite-encefalite caprina. Tese de Doutorado em Medicina Veterinária, Área de concentração Vigilância Sanitária, Faculdade de Medicina Veterinária e Zootecnia, Campus de Botucatu, Universidade Estadual Paulista, Botucatu, SP. 105p.
Thrusfield M.V. 2004. Epidemiologia Veterinária. 2ª ed. Ed. Roca, São Paulo. $556 \mathrm{p}$.

Van Der Puije W.N.A., Bosompem K.M., Canacoo E.A., Wastling J.M. \& Akanmori B.D. 2000. The prevalence of anti-Toxoplasma gondii antibodies in Ghanaian sheep and goats. Acta Tropica 76(1):21-26.

Vieira L.S., Cavalcante A.C.R. \& Ximenes L.F. 1998. Epidemiologia e controle das principais parasitoses de caprinos nas regiões semi-áridas do Nordeste. Embrapa-CNPC, Sobral. 50p.

Vitor R.W.A.O., Pinto J.B. \& Chiari C.A. 1991. Eliminação de Toxoplasma gondii através de urina, saliva e leite de caprinos experimentalmente infectados. Arq. Bras. Vet. Zootec. 43:147-154.

Zar J.H. 1995. Biostatistical Analysis. $4^{\text {th }}$ ed. Prentice Hall, Upper Saddle River. 663p. 